\title{
Inhibition of delay of the two-way avoidance response and warning-signal salience
}

\author{
KAZIMIERZ ZIELIŃSKI and TOMASZ WERKA \\ Nencki Institute of Experimental Biology, Warsaw, Poland \\ W. JEFFREY WILSON \\ Indiana University-Purdue University, Fort Wayne, Indiana \\ and \\ EUGENIUSZ NIKOLAEV \\ Nencki Institute of Experimental Biology, Warsaw, Poland
}

\begin{abstract}
Effects of extended training (nine sessions, 50 trials each) on two-way avoidance response latencies were studied. For each rat, auditory and visual warning signals (CS) were presented on separate trials, either according to a Gellermann series or in 25-trial blocks. Intermittent presentation of the two kinds of trials yielded shorter latencies and higher levels of avoidance performance in response to the noise CS than in response to the darkness CS. Presentation of trials in blocks revealed stronger response-eliciting properties of stimuli presented during the second half of the session than of those presented during the first half. A significant decrease of avoidance performance in the early portions of the delay period, an index of inhibition of delay, was obtained on auditory trials presented in the second half of the sessions. Results indicate that strong fear of the warning signal is required for inhibition of delay of avoidance responses.
\end{abstract}

Two-way avoidance training typically results in a gradual increase in the proportion of crossing responses performed during the warning-signal period, and a corresponding decrease in responses during subsequent aversive stimulation. At the outset of training, the rat changes compartments in response to painful stimulation. Fleeing, an innate species-specific defense reaction of rats (Bolles, 1970, 1971), soon becomes the dominant mode of behavior to pain and also to the events signaling painful stimulation. The data showing that escape and avoidance response latencies do not change in the course of training conducted in the shuttlebox (Bolles, Moot, \& Nelson, 1976) were in agreement with such an understanding of instrumental defensive responding.

A number of experiments yielded results that opposed the assertion of Bolles et al. (1976) concerning the invariance of response latencies in shuttlebox avoidance learning. Shortening of the two-way avoidance response latency was noted during a single training session (Bond, 1981; Galvani \& Twitty, 1978). In Starr and Mineka's (1977) experiments, the mean avoidance response latency

The present research was supported by a statutable grant from the State Committee for Scientific Research to the Nencki Institute. We thank W. Lawicka and B. Zernicki for their comments on an earlier draft of this paper. Correspondence should be addressed to $\mathrm{K}$. Zielinski, Nencki Institute of Experimental Biology, 3 Pasteur St., 02-093 Warsaw, Poland (e-mail: ziel@nencki.gov.pl.).

-Accepted by previous editor, Vincent M. LoLordo shortened by half a second between the first three and the last three avoidances in a series of 27 consecutive nonshock trials. In the W. R. McAllister, D. E. McAllister, Dieter, and James (1979) study, significant shortening of the avoidance response latency was observed during the second session in rats trained with strong, but not with weak, shock.

It seems, however, that during extended training, more complex changes in avoidance response latencies occurred. In our recent experiments on rats trained in twoway avoidance, a shortening of avoidance latencies within each session was observed, together with a significant lengthening of median avoidance latencies across sessions of extended training. Prolongation of avoidance response latency in the course of nine 50-trial sessions was more marked in rats trained with a noise signal than in rats trained with a darkness signal. More importantly, the probability of performing an avoidance response in the first half of the signal-shock interval decreased in the course of training (Zieliński, Werka, \& Nikolaev, 1993).

All consecutive versions of the two-process avoidance theory (e.g., D. E. McAllister, W. R. McAllister, \& Dieter, 1976; Mowrer, 1947; Rescorla \& Solomon, 1967; Solomon \& Wynne, 1953) postulate a role for Pavlovian conditioning in avoidance learning. Pairings of a warning signal (conditioned stimulus, CS) with an aversive unconditioned stimulus (US) on early training trials result in conditioning of a fear response to the CS. The observed change in the distribution of avoidance response latencies may be inter- 
preted as resulting from the development of Pavlovian inhibition of delay. Pavlov's analysis of delayed conditioning was based substantially on data from defensive acid reflexes. The only method proposed by Pavlov for testing whether a decrease in response latency was due to inhibition of delay was the presentation of a new external stimulus together with the original CS. The acquired inhibitory nature of the early phases of the CS was proved when this new stimulus enhanced salivation in the early phases of the CS-US interval, and decreased conditioned salivation in the late phases (disinhibition and external inhibition, respectively; Pavlov, 1927). We recently confirmed the inhibitory nature of changes in the distribution of avoidance responses by this method. In well-trained rats, a change from a darkness CS to a darkness-and-noise compound increased the number of avoidance responses in the early portion of the CS-US interval and decreased avoidance performance later on. Moreover, we also showed that inhibition of delay was destroyed after reinstatement of fear of situational cues (Zieliński et al., 1993).

The degree of intertrial responding is related to the amount of fear of the contextual cues (Callen, 1986; Mowrer \& Lamoreaux, 1951). Differing levels of fear of the CS and of the situational cues may be achieved by using stimuli of different modalities. In our experiments, rats trained with an auditory CS showed rapid avoidance learning and reached a high level of avoidance performance combined with a low intert rial response (ITR) rate. In contrast, when changes in illumination of the shuttlebox were used as a CS, rats learned the avoidance response slowly, reached a lower level of avoidance performance, and exhibited a high ITR rate (Zieliński, Werka, \& Nikolaev, 1991). Inhibition of delay was observed only when a salient CS was presented on a background of low ITR rates. A hypothesis was proposed that conditions necessary for the development of inhibition of delay in an aversive situation include a high fear of the CS terminated by an instrumental response and a low level of fear of situational cues. This inference was based on data obtained from several groups of rats, each trained with one $\mathrm{CS}$ and finally subjected to transfer tests (Zieliński et al., 1993).

The aim of the present study is to test whether the temporal pattern of avoidance responding depends only on the warning-signal salience, or whether it is rather a consequence of an interaction between the level of fear elicited by the warning signal and the level of fear conditioned to situational cues. Training conducted under conditions of mixed trials of salient (noise) and weak (darkness) CSs contrasts the two possibilities. The darkness $C S$ resulted in a high ITR rate, indicating enhanced fear of contextual cues. However, saliency of the noise CS presented in separate trials should not be changed. Regular formation of inhibition of delay of the avoidance response to the noise CS may be expected, if this learning process depends only on salience of the warning signal. In contrast, no inhibition of delay to the CS of either modality should be observed if a low level of fear of contextual cues is an indispensable condition.
Within-session comparisons showed that avoidance response latencies were shorter toward the end of each consecutive training session than they were at the beginning. The increase in avoidance performance and the shortening of avoidance latency were pronounced during the early training sessions and, presumably, reflect behavioral activation elicited by high shock frequency at the start of each such session (Zieliński et al., 1993). These changes indicate enhancement of the response-eliciting properties of the CS in the course of a training session and suggest the importance of the particular order of noise and darkness trials employed.

In the present experiment, each rat was confronted with the visual stimuli and the auditory stimuli presented on separate trials given either in an unpredictable order or in blocks. For each group of rats, data were collected and analyzed separately for avoidance responses and for escape responses, for each CS modality, and for the first and for the second half of the session.

\section{METHOD}

\section{Subjects}

The experiment was conducted with 16 adult male Möll-Wistar rats bred in the Nencki Institute, experimentally naive, and weighing $320-360 \mathrm{~g}$. The subjects were kept in groups of 8 in a single home cage ( $43 \mathrm{~cm}$ long, $25 \mathrm{~cm}$ wide, $18.5 \mathrm{~cm}$ high), containing food and water that were available ad lib. A natural light:dark cycle from external illumination was maintained. The rats were trained once a day in the morning or early afternoon, in the same order and at about the same time each day.

\section{Apparatus}

The shuttlebox apparatus was $62 \mathrm{~cm}$ long, $18 \mathrm{~cm}$ wide, and $29 \mathrm{~cm}$ high with walls of opaque dark Plexiglas. The box was divided in half by an insert with a rectangular $(7 \mathrm{~cm}$ wide, $10 \mathrm{~cm}$ high) cutout situated on the grid-floor level permitting passage from one side of the shuttlebox to the other. Each compartment was covered by a movable transparent Plexiglas ceiling and was illuminated by a $5-\mathrm{W}$ lamp mounted cent rally just below the ceiling. On each wall opposite to the central partition, a 10 -cm-high loudspeaker was mounted outside the apparatus, $15 \mathrm{~cm}$ above the floor. The response of crossing through the opening was recorded by photocells mounted $4 \mathrm{~cm}$ to either side of the central partition, $5 \mathrm{~cm}$ above the floor level. The floor in each compartment was constructed from 16 stainless steel bars, $0.4 \mathrm{~cm}$ in diameter, and located parallel to the central partition $1.5 \mathrm{~cm}$ apart from each other. The shuttlebox apparatus was placed in a dark, soundproof room. The subjects' behavior was watched on a TV monitor in an adjoining room, where equipment for automatic programming of the experiment and recording of data was located.

\section{Procedure}

Prior to avoidance training, each rat was habituated to the situational cues of the apparatus for $10 \mathrm{~min}$ on 2 consecutive days. At the beginning of each training session, the rat was placed in the left compartment of the shuttlebox, close to and facing the end wall. After $20 \mathrm{sec}$, a trial started with CS onset; $5 \mathrm{sec}$ later, the nominal 1.6-mA scrambled, pulsed dc shock was delivered through the grid floor (US). Running to the opposite compartment within the 5-sec CS-US interval precluded the footshock, immediately terminated the CS, and was scored as an avoidance response. Running to the opposite compartment after the US onset immediately coterminated the CS and the US, and was scored as an escape response. The maximal shock duration was $30 \mathrm{sec}$. Each daily training ses- 
sion consisted of 50 trials. The intertrial intervals (ITIs) were of $15-25 \mathrm{sec}$ duration (mean $=20 \mathrm{sec}$ ) and varied in a semirandom order. During the ITI, the subjects were permitted to move in any direction, so they could cross away from or back into the compartment in which they had been previously. The next trial always started in the compartment where the subject was located at the end of the ITI.

\section{Group Treatment}

Prior to the experiment, the rats were assigned randomly to four groups of 4 subjects each. Avoidance training started the day after habituation sessions. All rats were trained with two warning stimuli, one auditory and one visual, each presented on separate trials. The onset of a 70-dB (SPL) wide-band (white) noise was the auditory CS. The visual CS was darkness provided by termination of the ceiling light in the compartment occupied by the rat. Just after a rat left the shock compartment, the compartment was again lighted; both compartments were illuminated during auditory trials and ITIs. During each of nine daily sessions, there were 25 trials with noise CS and 25 trials with darkness CS.

The groups differed in the order of trials in which stimuli of different modalities were presented. In two groups, different stimuli were presented according to a Gellermann (1933) series; the same pattern was used in every session. In Group $A G$, each session started with the auditory CS, and in Group VG, the visual CS was given on the first trial. Thus, the order of noise and darkness trials for one group was a mirror image of the order for the other group. In the other two groups, stimuli of the same modality were given in 25-trial blocks, For Group AB, each daily session started with a block of auditory CS trials followed by a block of visual CS trials. The opposite order of 25-trial blocks was used for Group VB.

For each rat, the number of trials to the criteria of $3,10,20$, and 30 consecutive avoidance responses was calculated. For the purpose of data analysis, a rat that failed to reach criterion was assigned a score equal to the number of its last escape trial. This practice, by assuming that the final series of avoidances would have continued until criterion was achieved, will tend to underestimate the actual number of trials that would have been required for the rat to reach criterion.

All other measures of behavior (frequency of avoidance responding, response latency, and number of ITRs performed after termination of the trial) were collected and analyzed separately for auditory and visual trials and, similarly, for the first and the second half of each session. The latencies of instrumental responses were measured with an electronic timer, accurate to $0.1 \mathrm{sec}$.

\section{RESULTS}

\section{Avoidance Performance and ITR Rate}

Only two rats, one from Group $A B$ and one from Group VB, did not reach the criterion of 30 consecutive avoidances. The overall average numbers of trials for all the rats that reached the criteria of $3,10,20$, and 30 consecutive avoidance responses were $23.5,44.8,84.9$, and 136.6 trials, respectively. The mixed-design analysis of variance (ANOVA) on the number of trials to the consecutive criteria (not including the criterion trials) yielded an effect of criterion $[F(3,36)=14.68, p<.001]$, but no effect of group, and no interaction.

Analyses done only for rats in which the two kinds of trials were presented according to Gellermann (1933) series showed no effect of modality of the stimulus initiating a session. Thus, for all further analyses, the data for Group AG and Group VG were combined to serve as the reference for data of Group AB and Group VB. The changes in avoidance responding in consecutive sessions, independently for the first and for the second half of the session, are presented in Figure 1.

The data indicate that avoidance performance was strongly influenced by the CS modality and also by stimulus arrangement. Initially, during the first 25 trials, frequency of avoidance responding was similar in all groups. Group VB performed markedly better than Group $A B$ as early as the second half of the first session. Further, performance to the visual $\mathrm{CS}$ in Group $\mathrm{AB}$ was markedly lower than that in Groups AG and VG. This difference decreased over the following sessions. A 2 (stimulus) $\times 2$ (arrangement) $\times 9$ (day) ANOVA for repeated measures from the second half of sessions yielded effects of stimulus $[F(1,20)=22.20, p<.001]$, arrangement $[F(1,20)=6.77, p<.002]$, and day $[F(8,160)=$ $8.19, p<.001]$, and a day $\times$ arrangement interaction $[F(8,160)=2.10, p<.05]$. An analogous ANOVA for Trials $1-25$ showed only effects of stimulus $[F(1,20)=$ $5.01, p<.05]$ and day $[F(8,160)=52.52, p<.001]$.

ITR rate was similarly analyzed. As seen in Figure 2, the lowest ITR rate was observed during Trials $1-25$ of the first session. Then an increase was observed in each group. In Groups AG and VG, the ITR rate fluctuated from session to session, but was alike after both kinds of trial. On the contrary, a pronounced effect of stimulus modality on ITR rate was observed when CSs were presented in blocks (darkness in Group VB and noise in Group AB). ITR rate was higher after darkness than it was after noise. An ANOVA for the first half of sessions yielded effects of stimulus $[F(1,20)=5.50, p<$ $.05]$ and day $[F(8,160)=10.90, p<.001]$, and a stimu-

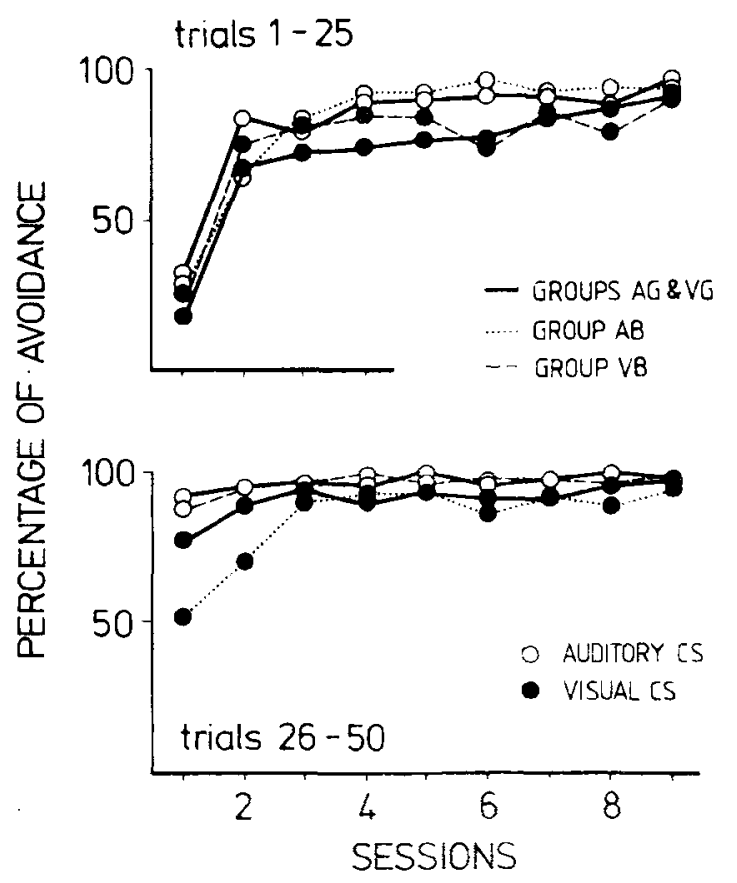

Figure 1. Percentage of avoidance responses during the first half (top) and the second half (bottom) of consecutive sessions. 


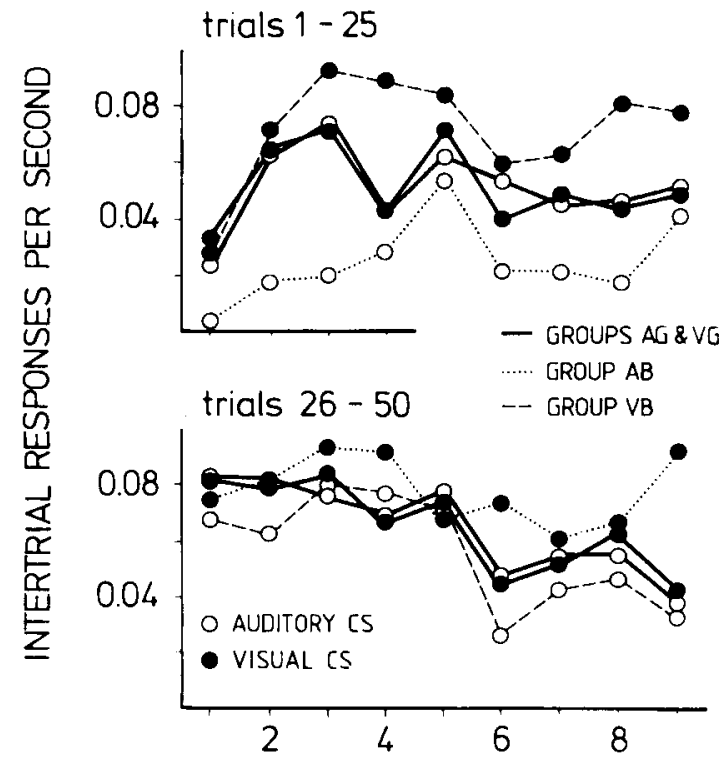

Figure 2. The rate of intertrial responses during the first half (top) and the second half (bottom) of consecutive sessions after auditory trials and after visual trials.

lus $X$ arrangement interaction $[F(1,20)=12.70, p<$ $.002]$.

It has to be stressed, however, that neither modality nor stimulus arrangement exerted any effect on ITR rate during Trials 26-50. An analogous ANOVA for the second half of sessions showed only an effect of day $[F(8,160)=5.46, p<.001]$, whereas the effect of stimulus $[F(1,20)=0.99]$ and the stimulus $\times$ arrangement interaction $[F(1,20)=1.68]$ were negligible. The effect of day was related to the decrease of the rate of ITRs toward the end of training.

\section{Response Latencies}

The pronounced effect shown above of stimulus arrangement on avoidance performance during the early training sessions was supported by analyses of response latencies. The cumulative frequency distributions of avoidance and escape responses, emitted in consecutive 0.5 -sec intervals after CS onset during Days 1,2, and 9, independently for auditory and visual trials, have been constructed. Data for the first half of the sessions are presented in Figure 3, while Figure 4 shows similar data for the second half of the sessions. Data from Groups AG and VG are in the top panels, whereas data from Group AB and from Group VB are in the bottom panels.

Distributions of response latencies to the darkness CS presented during Trials 1-25 (Figure 3) suggested that shortening of latencies in the course of training was comparable both for the visual stimulus given intermittently (top left panel) and for that given in homogeneous blocks (bottom left panel). A similar course of change was also observed for the auditory CS presented in blocks (bottom right panel). In contrast, shortening of response latency to the auditory CSs interspersed with visual CSs occurred mainly during the second session. Further changes up to the ninth session were limited mainly to responses with latencies longer than $2.5 \mathrm{sec}$. This rapid enhancement of avoidance performance to the auditory CS in Groups AG and VG might be due to a contrast effect resulting from presentation of the salient noise stimulus being interspersed with presentation of the weak darkness stimulus. Moreover, comparison of the distributions for the second and the ninth sessions showed that with training, there was a small decrease of avoidance responses to the auditory CS with latencies equal to or less than $2 \mathrm{sec}$ (top right panel).

Such an inversion of the cumulative response latency distributions in the course of training was strongly pronounced on auditory trials during the second half of sessions (Figure 4). Both for Groups AG and VG (top right panel) and for Group VB (bottom right panel), the order of latency distributions (e.g., at the 2-sec point) was just the opposite to that which might be expected. A similar inversion of distributions for the second and the ninth sessions, but within the 2- to 4-sec part of the CS-US interval, was also observed on visual trials presented intermittently during the second half of the sessions (top left panel). A regular increase in the probability of the avoidance response throughout the CS-US interval was observed only for the visual stimulus given during Trials 26-50 (bottom left panel).

In an attempt to evaluate independently the within- and between-session changes of response latency, two different statistical methods were employed. The KolmogorovSmirnov two-sample test was used for comparison of the cumulative distributions of response latencies to the

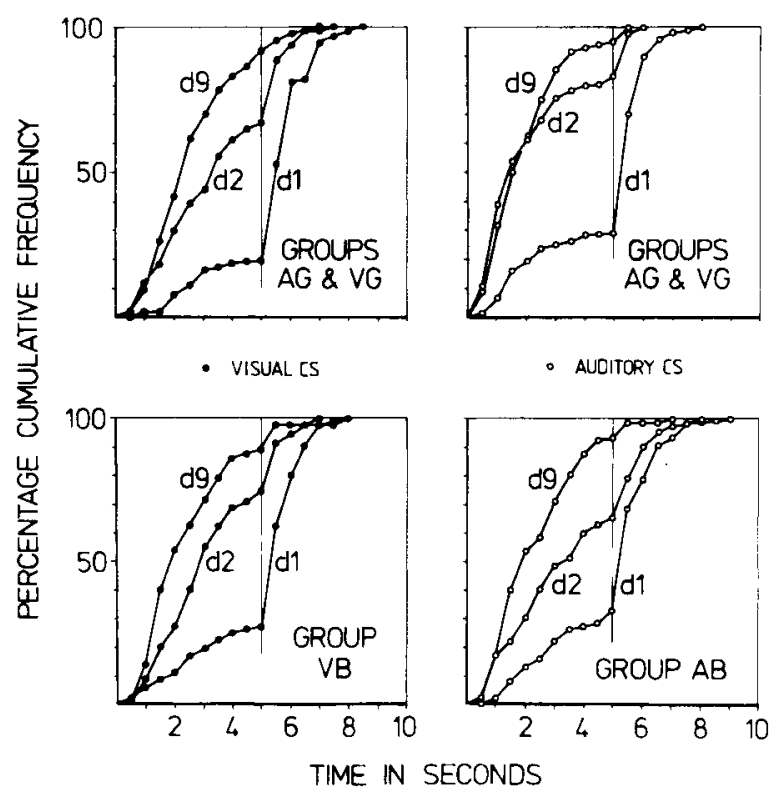

Figure 3. Cumulative frequency distribution of instrumental response latencies during the first half of the first, second, and ninth sessions. Left panels $=$ visual trials; right panels $=$ auditory trials; top row $=$ Groups $A G$ and VG; and bottom row $=$ Group VB and Group AB. 


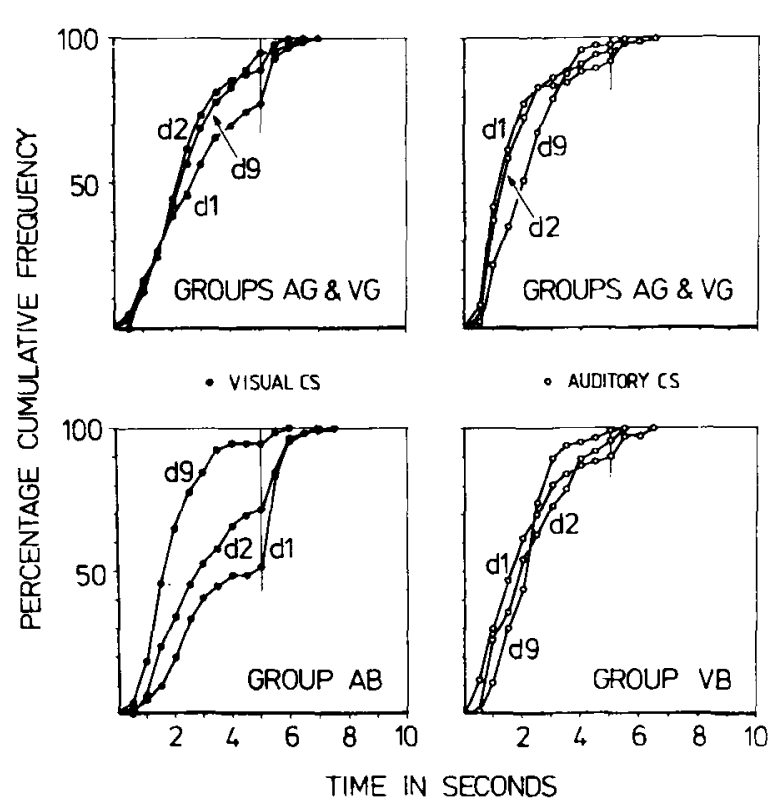

Figure 4. Cumulative frequency distribution of instrumental response latencies during the second half of the first, second, and ninth sessions. Left panels = visual trials; right panels = auditory trials; top row = Groups $A G$ and VG; and bottom row $=$ Group $A B$ and Group VB.

same CS presented in the first and in the second half of a given session. Obviously, this method can be applied only to data from Groups AG and VG.

Data presented in Table 1 indicate that for the visual $\mathrm{CS}$, the overall median latency of instrumental responses emitted during Trials $1-25$ was longer than that during Trials 25-50 within each session except the ninth. For the auditory CS, a shortening of the overall median response latency was less evident. The size of each sample compared in Table 1 was 100 response latencies. Magnitudes of the observed maximum vertical distance $\left(D_{\max }\right)$ between the two cumulative distributions showed that for the darkness CS, significant shortening of response latencies was observed within each of the first to the seventh training sessions. For the auditory stimulus, shortening of response latencies attained significance only during the first session. The points of $D_{\max }$ were located in the vicinity of the third sec of the CS-US interval, except for the first session, where the maximum vertical distance was located just after the US onset both on visual and on auditory trials.

As seen from Table 1, response latencies on auditory trials were shorter than those on visual trials. Since the whole distributions were compared by Kolmogorov-Smirnov tests, Table 1 contained median latencies of instrumental responses, either avoidance or escape. Comparisons based on median avoidance latencies for individual rats yielded similar relations between latencies for two kinds of trials and for halves of sessions (Table 2). The difference between the median avoidance latencies, calculated for each subject from trials grouped according to the four conditions within each session, decreased with training (Friedman two-way ANOVA).

It must be mentioned that differences between latencies on auditory and visual trials emerged in the course of training. Comparison of the first three avoidances performed to the noise CS and of the first three avoidances to the darkness CS by each rat from Groups AG and VG showed that these initial latencies of the avoidance responses do not differ $\left(z=0.45, n_{1}=n_{2}=24\right.$, Mann-Whitney $U$ test $)$.

The trend of changes in avoidance response latency in the course of training was calculated for five different points of the cumulative distribution functions. The percentages of responses emitted with latencies equal to or less than 1,2,3,4, and $5 \mathrm{sec}$ on consecutive sessions were compared within each group. For each time point, the Spearman rank correlation coefficient between the group mean percentage of avoidance responses and the number of the corresponding training session was obtained. A positive rho value indicates an increasing trend of the percentages of avoidance responses at a given time point, and a negative rho value indicates a decreasing trend. The larger the absolute value of the rho coefficient, the fewer distortions from monotonicity were observed in the course of training. The results of such a time-trend analysis are presented in Figure 5 for trials given in the first half of the sessions and in Figure 6 for

Table 1

Median Latencies (in Seconds) of Responses on Trials $1-25$ and $26-50$ and $D_{\max }$ Value (in Percent) Between Cumulative Distributions of Responses

\begin{tabular}{|c|c|c|c|c|c|c|}
\hline \multirow[b]{3}{*}{ Session } & \multicolumn{3}{|c|}{ Visual CS } & \multicolumn{3}{|c|}{ Auditory CS } \\
\hline & \multicolumn{2}{|c|}{ Trials } & \multirow[b]{2}{*}{$D_{\max }$} & \multicolumn{2}{|c|}{ Trials } & \multirow[b]{2}{*}{$D_{\max }$} \\
\hline & $1-25$ & $26-50$ & & $1-25$ & $26-50$ & \\
\hline 1 & 5.5 & 2.7 & 61 & 5.4 & 1.2 & 64 \\
\hline 2 & 3.3 & 2.2 & 32 & 1.3 & 1.3 & 16 \\
\hline 3 & 2.5 & 1.8 & 28 & 1.5 & 1.3 & 18 \\
\hline 4 & 2.9 & 1.9 & 25 & 1.5 & 1.3 & 10 \\
\hline 5 & 2.4 & 2.0 & 21 & 1.7 & 1.3 & 19 \\
\hline 6 & 3.2 & 2.2 & 24 & 1.5 & 1.6 & 11 \\
\hline 7 & 2.8 & 1.9 & 22 & 1.9 & 1.6 & 15 \\
\hline 8 & 2.2 & 1.9 & 18 & 1.9 & 1.9 & 14 \\
\hline 9 & 2.2 & 2.3 & 5 & 1.5 & 2.0 & 18 \\
\hline
\end{tabular}

Note-For $n_{1}=n_{2}=100$ sample sizes, critical value of $D_{\max }$ is $19.2 \%$ for $p=.05$, $23.1 \%$ for $p=.01$, and $27.6 \%$ for $p=.001$. 
Table 2

Group Mean From Individual Median Avoidance Latencies (in Seconds) Compared Within Each Session

\begin{tabular}{|c|c|c|c|c|c|}
\hline \multirow[b]{3}{*}{ Session } & \multicolumn{4}{|c|}{ Trials } & \multirow[b]{3}{*}{$x^{2}$} \\
\hline & \multicolumn{2}{|c|}{ Visual CS } & \multicolumn{2}{|c|}{ Auditory CS } & \\
\hline & $1-25$ & $26-50$ & $1-25$ & $26-50$ & \\
\hline 1 & 2.4 & 2.0 & 2.3 & 3.1 & $10.50^{*}$ \\
\hline 2 & 2.6 & 2.0 & 1.1 & 1.4 & $11.85 \dagger$ \\
\hline 3 & 2.2 & 1.9 & 1.3 & 1.4 & $14.44 t$ \\
\hline 4 & 2.4 & 1.7 & 1.2 & 1.5 & $12.15+$ \\
\hline 5 & 2.1 & 1.9 & 1.7 & 1.4 & 5.06 \\
\hline 6 & 2.6 & 2.1 & 2.0 & 1.6 & 7.46 \\
\hline 7 & 2.5 & 2.1 & 1.4 & 1.6 & $12.11 \div$ \\
\hline 8 & 2.0 & 1.8 & 1.7 & 2.0 & 1.99 \\
\hline 9 & 2.1 & 2.4 & 1.4 & 2.1 & 7.05 \\
\hline
\end{tabular}

those given in the second half. Data from Groups AG and $\mathrm{VG}$ are in the top panels, whereas data from Group AB and from Group VB are in the bottom panels.

As was shown by the changes in the cumulative distributions of avoidance latencies for Trials 1-25 in Figure 3, the Spearman rho values for different points of the CS-US interval in Figure 5 indicate a steady increase in avoidance responses at each time point of the CS-US interval. For the first half of the sessions, the increase in frequency of avoidance responding was more regular toward the end of the CS-US interval than it was at the beginning, and was more regular on visual than on auditory trials. Moreover, higher rho values were observed for Groups $A G$ and $V G$ than for either Group AB or Group VB.

During the second half of the sessions (Figure 6), a different pattern of rho values was observed for the visual trials than was observed for the auditory trials. In general, a monotonic increase of avoidance responding to the darkness CS was observed at each point of CS-US interval, irrespective of the half of the session and stim-

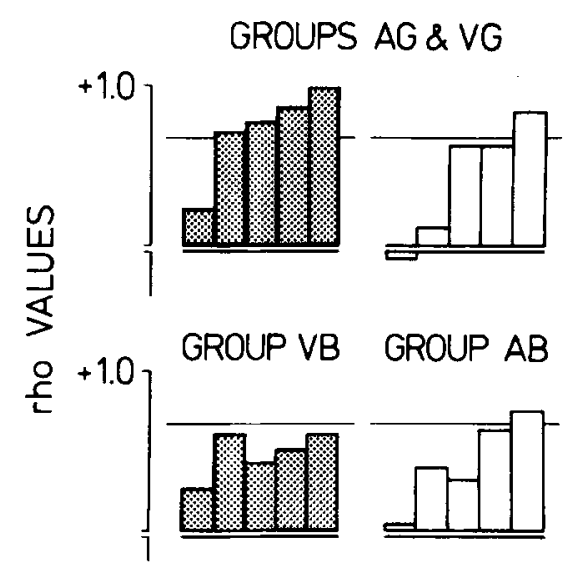

Figure 5. Values of the Spearman rank correlation coefficient between the number of avoidance responses performed during Trials $1-25$ up to and including $1,2,3,4$, and 5 sec in consecutive sessions and the number of the training session. The horizontal lines denote $p=.05$ rho values. Leff panels = visual trials (black bars); right panels = auditory trials (open bars); top row $=$ Groups $A G$ and VG; and bottom row = Group VB and Group $A B$. ulus arrangement. In Group AB, the positive correlation between the avoidance performance on visual trials and the number of training sessions reached significance at each point of the CS-US interval (bottom left panel, Figure 6). In contrast, another pattern of response-latency changes was observed to the noise CS given during the second half of the sessions. At the beginning of the CS-US interval, the number of avoidance responses decreased monotonically over the course of training, whereas during the second half of the CS-US interval, avoidance responses increased. The two opposite relations of avoidance performance with training reached significance for auditory trials given intermittently during the second half of sessions (top right panel, Figure 6). A similar pattern was observed in Group VB, but the monotonic decrease was significant only for avoidance responses with latencies of $1 \mathrm{sec}$ or less (bottom right panel, Figure 6).

During the first and the second sessions, all rats performed some number of escape responses. The median daily response latency on shock trials for individual rats varied from 5.10 to $6.40 \mathrm{sec}$ and did not differ across CS modality or training sessions. More escape responses were performed, and the variability of escape latencies was greater, when response-eliciting properties of the warning signal were weak, as was the case early in training, at the beginning of a session, or due to low salience of the CS.

\section{DISCUSSION}

The present study confirmed the assumptions formulated on the basis of earlier data and showed that salience of the warning signal is the main factor influencing formation of inhibition of delay in the two-way avoidance situation. A method of mixed presentation of salient and weak stimuli resulted in conditioning of a strong fear of situational cues in each group of this experiment. Contextual fear did not preclude development of the two opposite patterns of between-session changes in avoidance response latencies described for stimuli of different saliency: (1) a steady increase over sessions of responding at any point in the CS-US interval to weak stimuli; and (2) a decrease of avoidance performance in the early portions of the CS-US interval for salient stimuli.

The temporal characteristics of instrumental avoidance responses depended on warning-stimulus quality. The intermittent presentation of the auditory and visual stimuli permitted a within-subject comparison of the response-eliciting properties of the stimuli. By this method, the superiority of avoidance performance to the noise CS over that to the visual CS early in training was confirmed. In the present experiment, a very pronounced shortening of avoidance response latencies to the noise $\mathrm{CS}$ within the first session was shown. The shortening of avoidance response latencies to the darkness CS was much smaller during the same session. The resulting difference between median avoidance latencies to the two kinds of stimuli decreased during further training. Avoidance re- 


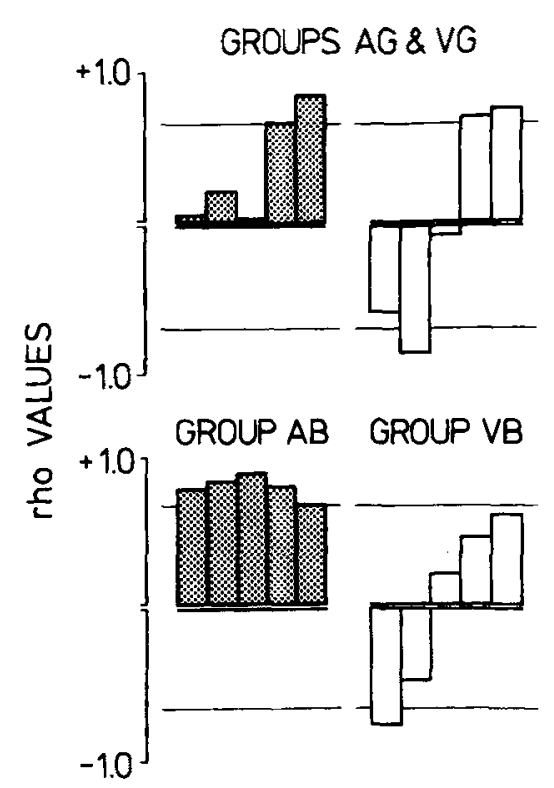

Figure 6. Values of the Spearman rank correlation coefficient between the number of avoidance responses performed during Trials 26-50 up to and including $1,2,3,4$, and 5 sec in consecutive sessions and the number of the training session. The horizontal lines denote $p=.05$ rho values. Left panels $=$ visual trials (black bars); right panels = auditory trials (open bars); top row = Groups AG and VG; and bottom row = Group AB and Group VB.

sponse latencies to the noise CS lengthened within many of the following sessions, whereas median avoidance latencies to the darkness CS shortened during all but the last training session.

The arrangement of the two kinds of trials within the session influenced the course of training. When the different stimuli were presented according to a Gellermann (1933) series, consistently more avoidance responses were performed to the auditory CS than to the visual CS. Presentation of the two kinds of stimuli in blocks affected the differences in the response-eliciting properties of the stimuli. During the first session, the largest difference in avoidance performance was obtained when the darkness CS was presented in the first, and the noise $\mathrm{CS}$ in the second, 25-trial block (Group VB). In contrast, more avoidances were performed to the darkness CS than to the noise CS when the visual (darkness) CS was given after the block of auditory (noise) trials (Group AB). Clearly, the response-eliciting properties of a stimulus were stronger when it was presented during the second of the session half than when it was presented during the first half. These differences decreased in the course of training.

With extended avoidance training, fear of the CS as measured in the conditioned emotional response procedure decreases (Kamin, Brimer, \& Black, 1963; Linden, 1969; Mineka \& Gino, 1980; Weisman \& Litner, 1972). The attenuation of fear over the course of avoidance training was interpreted originally as an extinction process due to the increase of the number (and/or proportion) of CS presentations not accompanied by painful stimula- tion. The purely Pavlovian contingency between the CS and US cannot, however, account for the quicker extinction of fear after prolonged training. Comparison of rats trained in two-way avoidance and their yoked partners showed that nonreinforced CS presentations do not contribute to the attenuation of fear. Such a role is played, rather, by the feedback provided by an avoidance response (Starr \& Mineka, 1977).

Another method for measuring the changes of fear permits a rat to escape, in the absence of shock, from the shuttlebox to an adjacent safe box (W. R. McAllister, D. E. McAllister, \& Benton, 1983; W. R. McAllister et al., 1979). A decrease of fear of the warning signal after a long run of successive avoidance trials was confirmed with this method and, additionally, the maintenance of high level of fear of situational cues was shown. On the basis of these and some other data, McAllister and colleagues proposed that the effective reinforcement for an avoidance response is positively related to the amount of fear reduction occurring with termination of the CS, and negatively related to the amount of fear present after the response (D. E. McAllister et al., 1976; W. R. McAllister, D. E. McAllister, \& Douglass, 1971).

The effective reinforcement theory suggests possibilities for experimental investigation of the processes involved in changes of avoidance response latencies. Comparison of separate groups showed that rats trained with an auditory CS rapidly acquired a high level of two-way avoidance performance combined with a very low ITR rate. In contrast, when changes in illumination of the shuttlebox were used as a CS, rats learned avoidance slowly, reached a lower level of avoidance performance, and exhibited a high ITR rate (Zieliński et al., 1991). During extended training, the avoidance response latencies became longer, more so in rats trained with the noise $\mathrm{CS}$ than in rats trained with the darkness CS. The latency changes were related to a decrease in the probability of avoidance responses in the first half of the CS-US interval. These changes in the distribution of avoidance response were destroyed after the reinstatement of fear of situational cues (Zielinski et al., 1993).

The present experiment explores further the conditions necessary for formation and maintenance of inhibition of delay of the avoidance response. If one accepts the notions that the ITR rate is an index of fear conditioned to the experimental context (Callen, 1986; Mowrer \& Lamoreaux, 1951; Owen, Cicala, \& Herdegen, 1978; Zieliński, 1993) and that high avoidance performance combined with low ITR rate denotes successful fear reduction after the CS termination, the results of the present experiment may be considered as confirmation of the hypothesis proposed recently (Zieliński et al., 1993). Presentation of auditory and visual stimuli during the same session resulted in maintenance of a high level of fear of situational cues. Independently of the arrangement of the two kinds of trials, the ITR rate was high in each group and comparable to that observed when only a visual CS was used in all trials (Zieliński et al., 1991). 
Training conducted in these conditions resulted in a steady increase in avoidance responses to the darkness $\mathrm{CS}$ at any point in the CS-US interval. During the first half of the sessions, a similar pattern of avoidance performance was observed also to the more salient noise CS. However, a significant decrease of avoidance performance in the early portions of the CS-US interval, an index of inhibition of delay, was obtained on auditory trials presented in the second half of the sessions. An enhancement of the response-eliciting properties of the CS in the course of a training session described before (Zieliński et al., 1991, 1993) and a possible contrast effect from the earlier and/or intermittent presentations of a weak visual stimulus may be the factors increasing salience of the noise CS.

Collectively, the results of the present and the previous experiments emphasize the importance of Pavlovian fear conditioned to the CS for avoidance performance. The inhibition of delay of the two-way avoidance response very likely is a result of inhibition of delay of Pavlovian fear; however, this view has to be verified in special experiments.

Originally, the method for training the inhibition of delay consisted of transformation of short-delay conditioned responses to those with long delay (Pavlov, 1927). In experiments employing the CER method, it was shown that reliable inhibition of delay of a classically conditioned defensive response may be obtained with long CS-US intervals of constant duration (Hammond \& Maser, 1970; Hendry \& Van-Toller, 1965; Millenson \& Hendry, 1967; Zieliński, 1966; Zieliński \& Walasek, 1977). It was thought that inhibition of delay develops slowly and cannot be applied to explain within-session response decrement early in training (Ayres, BergerGross, Kohler, Mahoney, \& Stone, 1979). However, marked decrease of the response rate in the early part of the CS-US interval was observed after only a few sessions with Pavlovian fear conditioning superimposed on a Sidman avoidance schedule (Rescorla, 1967). The present experiment showed that in special conditions, a decrease of responses in the early phases of the CS-US interval occurred as early as the second 50-trial session. The conditions consisted of presentation of a salient CS during the second half of the session, on a background of enhanced behavioral activation due to high shock density related to the use of a less salient stimulus at the beginning of the session.

Nearly thirty years ago, on the basis of experiments applying an avoidance contingency to autonomically mediated electrodermal response (GSR), Kimmel (1966) formulated an opinion denying any adaptive role of Pavlovian inhibition of delay in the avoidance paradigm. We consider, instead, the latency of a response as an index of a central nervous system state. If one accepts the role of Pavlovian conditioning processes in mediating and evoking the instrumental response, the possible role of Pavlovian inhibition of delay in normalizing temporal parameters of instrumental responses cannot be rejected. Our data showed that development of inhibition of delay is only one element in the evolution of the two-way avoidance response latency. The relations between fear elicited by the warning-signal onset and fear conditioned to situational cues change during each session and also in consecutive sessions. All of the within- and betweensession changes described have in common the decrease of variability of the instrumental response latency in the course of extended two-way avoidance training.

\section{REFERENCES}

Ayrfs, J. J. B., Bfrger-Gross, P., Kohler, E. A., Mahoney, W. J., \& STONE, S. (1979). Some orderly nonmonotonicities in the trial-bytrial acquisition of conditioned suppression: Inhibition with reinforcement? Animal Learning \& Behavior, 7, 174-180.

Bolles, R. C. (1970). Species-specific defense reactions and avoidance learning. Psychological Review, 77, 32-48.

Bolles, R. C. (1971). Species-specific defense reactions. In F. R. Brush (Ed.), Aversive conditioning and learning (pp. 183-233). New York: Academic Press.

Boli.es, R. C., MoOt, S. A., \& Nelson, K. (1976). Note on the invariance of response latency in shuttlebox avoidance learning. Learning \& Motivation, 7, 108-116.

BOND, N.W. (1981). A re-examination of response latency in shuttlebox avoidance learning. Australian Journal of Psychology, 33, 253256.

CAllen, E. J. (1986). Fear of the CS and of the context in two-way avoidance learning: Between- and within-subjects manipulations. Animal Learning \& Behavior, 14, 80-89.

Gal.vant, P. F., \& TwitTy, M. T. (1978). Effects of intertrial interval and extcroceptive feedback duration on discriminative avoidance acquisition in the gerbil. Animal Learning \& Behavior, 6, 166-173.

GellermanN, L. W. (1933). Chance orders of alternating stimuli in visual discrimination experiments. Joumal of Genetic Psychology, 42. 206-208

Hammond, L. J., \& MASER, J. (1970). Forgetting and conditioned suppression: Role of a temporal discrimination. Journal of the Experimental Analysis of Behavior, 13, 333-338.

Hendry, D. P., \& VAN-Toller, C. (1965). Alleviation of conditioned suppression. Journal of Comparative \& Physiological Psychology, 59, 458-460.

Kamin, L. J., Brimer, C. J., \& Black, A. H. (1963). Conditioned suppression as a monitor of fear of the CS in the course of avoidance training. Journal of Comparative \& Physiological Psychology, 56. 497-501

Kummel, H. D. (1966). Inhibition of the unconditioned response in classical conditioning. Psychological Review, 73, 232-240.

LINDEN, D. R. (1969). Attenuation and reestablishment of the CER by discriminated avoidance conditioning in rats. Journal of Comparative \& Physiological Psychology, 69.573-578.

MCAllister, D. E., MCAllister, W. R., \& Dieter, S. E. (1976). Reward magnitude and shock variables (continuity and intensity) in shuttlebox-avoidance learning. Animal Learning \& Behavior, 4, 204-209.

MCAllister, W. R., MCAllister, D. E., \& Benton, M. M. (1983). Measurement of fear of the conditioned stimulus and of situational cues at several stages of two-way avoidance learning. Learning \& Motivation, 14, 92-106.

MCAllister, W. R., MCAleister, D. E., Dieter, S. E., \& James, J, H. (1979). Preexposure to situational cues produces a direct relationship between two-way avoidance learning and shock intensity. Animal Learning \& Behavior, 7, 165-173.

McAlister, W. R., McAllister, D. E., \& Douglass, W. K. (1971) The inverse relationship between shock intensity and shuttle-box avoidance learning in rats: A reinforcement explanation. Joumal of Comparative \& Physiological Psycholog., 74, 426-433.

Millenson, J. K., \& Hendry, D. P. (1967). Quantification of response suppression in conditioned anxiety training. Canadian Journal of Psychology, 21, 242-252.

MineKa, S., \& Gino, A. (1980). Dissociation between conditioned 
emotional response and extended avoidance performance. Learning \& Motivation, 11, 476-502.

Mowrer, O. H. (1947). On the dual nature of learning-a re-interpretation of "conditioning" and "problem-solving." Harvard Educational Review, 17, 102-148.

Mowrer, O. H., \& LAmoreaux, R. R. (1951). Conditioning and conditionality (discrimination). Psychological Review, 58, 196-212.

Owen, J. W., Cicala, G. A., \& Herdegen, R. T. (1978). Fear inhibition and species specific defense reaction termination may contribute independently to avoidance learning. Learning \& Motivation, 9, 297-313.

Pavlov, I. P. (1927). Conditioned reflexes: An investigation of the physiological activity of the cerebral cortex (G. V. Anrep, Ed. and Trans.). London: Oxford University Press.

Rescorla, R. A. (1967). Inhibition of delay in Pavlovian fear conditioning. Journal of Comparative \& Physiological Psychology, 64, 114-120.

ResCorla, R. A., \& Solomon, R. L. (1967). Two-process learning theory: Relationships between Pavlovian conditioning and instrumental learning. Psychological Review, 74, 151-182.

SOLOMON, R. L., \& WYNNE, L. C. (1953). Traumatic avoidance learning: Acquisition in normal dogs. Psychological Monographs, 67, 1-19.

STARR, M. D., \& MINEKA, S. (1977). Determinants of fear over the course of avoidance learning. Learning \& Motivation, 8, 332-350.
Weisman, R. G., \& LitneR, J. S. (1972). The role of Pavlovian events in avoidance training. In R. A. Boakes \& M. S. Halliday (Eds.), Inhibition and learning (pp. 253-270). New York: Academic Press. ZIELIŃSKI, K. (1966). "Inhibition of delay" as mechanism of the gradual weakening of the conditioned emotional response. Acta Biologiae Experimentalis, 26, 407-418.

ZIELIŃSKI, K. (1993). Intertrial responses in defensive instrumental learning. Acta Neurobiologiae Experimentalis, 53, 215-229.

Zieliński, K., \& WalaseK, G. (1977). Stimulus intensity and conditioned suppression magnitude: Dependence upon the type of comparison and stage of training. Acta Neurobiologiae Experimentalis, 37, 299-309.

Zieliński, K., Werka, T., \& Nikolaev, E. (1991). Intertrial responses of rats in two-way avoidance learning to visual and auditory stimuli. Acta Neurobiologiae Experimentalis, 51, $71-88$

ZielińSKi, K., Werka, T., \& NikOlaEv, E. (1993). Latency of the twoway avoidance response in rats: Inhibition of delay hypothesis. Acta Neurobiologiae Experimentalis, 53, 535-545.

(Manuscript received September 10, 1993; revision accepted for publication October 15, 1994.) 